\title{
Efficacy of a dose-intensified CHOP (Double-CHOP) regimen for peripheral T-cell lymphomas
}

\author{
NORIYOSHI IRIYAMA $^{1 *}$, HIROMICHI TAKAHASHI $^{1 *}$, YOSHIHIRO HATTA $^{1}$, KATSUHIRO MIURA $^{1}$, \\ YUJIN KOBAYASHI $^{1}$, DAISUKE KURITA ${ }^{1}$, YUKIO HIRABAYASHI ${ }^{1}$, ATSUKO HOJO ${ }^{1}$, \\ HITOMI KODAIRA $^{1}$, MAI YAGI ${ }^{1}$, SATOMI KISO ${ }^{1}$, YOSHIHITO UCHINO ${ }^{1}$, MASARU NAKAGAWA ${ }^{1}$, \\ MACHIKO KUSUDA ${ }^{1}$, SUMIKO KOBAYASHI ${ }^{1}$, AKIRA HORIKOSHI $^{1}$, YOSHIMASA KURA ${ }^{2}$, \\ TETSUO YAMAZAKI ${ }^{1}$, UMIHIKO SAWADA ${ }^{2}$ and JIN TAKEUCHI $^{1}$ \\ ${ }^{1}$ Department of Hematology and Rheumatology, Nihon University School of Medicine, Itabashi-ku, Tokyo; \\ ${ }^{2}$ Division of Hematology and Oncology, Kasukabe Municipal Hospital, Kasukabe-shi, Saitama, Japan
}

Received September 17, 2012; Accepted October 23, 2012

DOI: 10.3892/or.2012.2143

\begin{abstract}
Peripheral T-cell lymphomas (PTCLs) are a rare and heterogeneous group of non-Hodgkin lymphomas, often resulting in poor prognoses. The $\mathrm{CHOP}$ chemotherapy regimen, which includes cyclophosphamide, doxorubicin, vincristine and prednisone, has been used previously to treat other types of lymphomas. Here, we examined the efficacy and safety of a dose-intensified CHOP regimen (Double-CHOP), which was followed by autologous stem-cell transplantation (ASCT) or high-dose methotrexate (HDMTX), in PTCL patients. Twentyeight PTCL patients, who received 3 courses of Double-CHOP at our institution, were retrospectively studied from 1996 to 2012. Patients with anaplastic lymphoma kinase-positive anaplastic large-cell lymphoma (ALK ${ }^{+}$-ALCL) were excluded from this study. The median age of patients was 58 years (range: 17-69). They had low-intermediate $(n=11)$, high-intermediate $(n=10)$ or high $(n=7)$ risk according to the International Prognostic Index (IPI). The overall complete remission (CR) rate following Double-CHOP treatment was 68\%. Of the CR patients, 10 successfully tolerated a consolidated high-dose chemotherapy followed by ASCT and 7 received HDMTX. A single case of treatment-related mortality was recorded during the study. On a median 31-month follow-up, the estimated 3- or 5 -year overall survival (OS) rates were 68 or $63 \%$, respectively, while 3- or 5-year relapse-free survival (RFS) rates after CR
\end{abstract}

Correspondence to: Dr Noriyoshi Iriyama, Department of Hematology and Rheumatology, Nihon University School of Medicine, 30-1 Oyaguchi Kamicho, Itabashi-ku, Tokyo 173-8610, Japan

E-mail: iriyama.noriyoshi@nihon-u.ac.jp

\section{*Contributed equally}

Key words: peripheral T-cell lymphoma, dose-intensified CHOP, autologous hematopoietic stem cell transplantation, high-dose methotrexate were 60 or $43 \%$, respectively. Although this study included elderly and excluded low-risk IPI and ALK ${ }^{+}$-ALCL patients, OS results were superiorly favourable, indicating the efficacy of this Double-CHOP regimen. However, an effective treatment strategy for refractory or relapsing patients needs to be validated and established.

\section{Introduction}

Peripheral T-cell lymphomas (PTCLs) constitute a rare, heterogeneous class of non-Hodgkin lymphomas (NHLs) characterised by generally poor prognoses. The most common PTCL subtypes are angioimmunoblastic T-cell lymphoma (AITL), peripheral T-cell lymphoma not-otherwise-specified (PTCL-NOS), and anaplastic-lymphoma-kinase (ALK)-positive or ALK-negative anaplastic large-cell lymphomas (ALCLs) (1).

PTCL patients are more likely to present with aggressive clinical features such as bone-marrow involvement, B symptoms, or other comorbidities $(1,2)$. Moreover, most patients are elderly (median age: $>60$ years), usually presenting with extra-nodal lymphoma sites and high serum LDH levels $(1,2)$.

A previously established, standard treatment for B-cell lymphomas is the R-CHOP combination chemotherapy, which includes rituximab, cyclophosphamide, doxorubicin, vincristine, and prednisone $(3,4)$. Although the $\mathrm{CHOP}$ regimen is the widely used first-line treatment for PTCLs, its effectiveness has not been established prospectively. Previous studies including relatively large numbers of cases have reported unfavourable prognoses with 5-year overall survival (OS) rates of $<40 \%(1,9-11)$ with the exception of ALK ${ }^{+}$-ALCL and primary cutaneous T-cell lymphomas (CTCLs). ALK ${ }^{+}$-ALCLs yield a more favourable outcome following conventional chemotherapy $(5,6)$ and primary CTCLs mostly take an indolent clinical course $(7,8)$. Because of reportedly low PTCL OS rates, many physicians strive to improve the results of $\mathrm{CHOP}$ or other comparable regimens, hoping to achieve better patient outcomes.

To establish effective treatment protocols for PTCLs and to improve patient outcomes, multiple clinical trials have been under- 
taken. For example, the SWOG clinical trials, which compared $\mathrm{CHOP}$ to second- or third-generation dose-intensive regimens indicated in aggressive lymphomas, established that CHOP was less toxic than, but as efficacious as, the new-generation intensive regimens. However, routine immunophenotyping was not performed in that study (12).

Autologous stem-cell transplantation (ASCT) is a promising, intensive, consolidating treatment option for refractory/ relapsing patients who underwent salvage therapies $(13,14)$. However, ASCT findings are controversial (15-19). It has been difficult to ascertain the significance of ASCT because i) many relevant studies have used relatively small study case numbers; ii) some have included $\mathrm{ALK}^{+}$-ALCL, which are known to lead to better outcomes than other T-cell lymphomas; and iii) ASCT has been performed in relatively younger PTCL patients.

In this study, we treated consecutive PTCL patients with our original dose-intensified CHOP, Double-CHOP. Patients achieving complete remission (CR) were subsequently treated with high-dose therapy (HDT)/ASCT, or high-dose methotrexate (HDMTX) treatment. Herein, we present our Double-CHOP and ASCT treatment outcomes.

\section{Patients and methods}

Patients. From December 1996 to February 2012, newly diagnosed adult PTCL patients, aged 15-69 years, including those with ALK-ALCL, AITL, PTCL-NOS, and $\gamma / \delta$ T-cell lymphoma were included in this study. Patients with other subtypes of T-cell lymphomas, including $\mathrm{ALK}^{+}$-ALCL, CTCLs, adult T-cell lymphoma (ATL), and those with lowgrade IPI risk or with localised lesions were excluded. Other exclusion criteria included Eastern Cooperative Oncology Group (ECOG) performance status (PS) of 4; markedly impaired cardiac, renal, or pulmonary functions; and positivity for hepatitis-B surface antigen. All patients underwent systemic computed tomography (CT) scans, bone-marrow aspiration and/or biopsy, and either gallium scintigraphy or positron-emission tomography (PET) for lymphoma staging. The study was approved by the institutional review board of our hospital.

Treatment. The Double-CHOP regimen consisted of 3 courses of intravenous (i.v.) administration of cyclophosphamide $\left(750 \mathrm{mg} / \mathrm{m}^{2}\right.$, days $1-2$, over $\left.2 \mathrm{~h}\right)$, doxorubicin $\left(50 \mathrm{mg} / \mathrm{m}^{2}\right.$, days $1-2,>30 \mathrm{~min})$, vincristine $\left(1.4 \mathrm{mg} / \mathrm{m}^{2}\right.$, day $1, \max 2 \mathrm{mg} /$ body), and per os (p.o.) prednisone $\left(50 \mathrm{mg} / \mathrm{m}^{2}\right.$, days 1-5). For patients aged $>60$, cyclophosphamide dose was modified as follows: course $1,750 \mathrm{mg} / \mathrm{m}^{2}$, day 1 ; course $2,500 \mathrm{mg} / \mathrm{m}^{2}$, days $1-2$; and course $3,750 \mathrm{mg} / \mathrm{m}^{2}$, days $1-2$. Treatment intensity was augmented during every course unless leukocyte recovery (WBC count, $<3,000$ on day 23) was delayed or an adverse event (grade $\geq 3$ ) other than haematological toxicities developed. When patients developed grade $\geq 3$ neutropenia, granulocyte colony-stimulating factor (G-CSF) was administered until neutrophil counts recovered. To administer subsequent courses of Double-CHOP, an absolute leukocyte count $\geq 3.0 \times 10^{9} / 1$, neutrophil count $\geq 1.0 \times 10^{9} / 1$, and platelet count $\geq 1 \times 10^{11} / 1$ were required. If patients were i) 65 years or younger, ii) had an acceptable ECOG PS, and iii) achieved complete remission (CR) or unconfirmed CR (CRu) within 3 courses of Double-
Table I. Patients characteristics.

\begin{tabular}{|c|c|c|}
\hline & $\mathrm{n}=28$ & $\%$ \\
\hline Median age (range) & $58(17-69)$ & \\
\hline Gender (male/female) & $20 / 8$ & \\
\hline \multicolumn{3}{|l|}{ PTCL type } \\
\hline PTCL-NOS & 13 & 46 \\
\hline AITL & 11 & 39 \\
\hline $\mathrm{ALK}^{-}-\mathrm{ALCL}$ & 3 & 11 \\
\hline$\gamma / \delta$ T-cell lymphoma & 1 & 4 \\
\hline \multicolumn{3}{|l|}{ ECOG performance status } \\
\hline $0-1$ & 11 & 39 \\
\hline $2-3$ & 17 & 61 \\
\hline \multicolumn{3}{|l|}{$\mathrm{LDH}$} \\
\hline Normal & 5 & 18 \\
\hline High & 23 & 82 \\
\hline \multicolumn{3}{|l|}{ Stage } \\
\hline $1-2$ & 2 & 7 \\
\hline $3-4$ & 26 & 93 \\
\hline \multicolumn{3}{|l|}{ Extranodal sites } \\
\hline $0-1$ & 23 & 82 \\
\hline$\geq 2$ & 5 & 18 \\
\hline \multicolumn{3}{|l|}{ Bone-marrow involvement } \\
\hline Yes & 8 & 29 \\
\hline No & 20 & 71 \\
\hline \multicolumn{3}{|l|}{ IPI risk factor } \\
\hline Low-intermediate (2) & 11 & 39 \\
\hline High-intermediate (3) & 10 & 36 \\
\hline High (4-5) & 7 & 25 \\
\hline \multicolumn{3}{|l|}{ PIT score } \\
\hline Group 1 & 7 & 25 \\
\hline Group 2 & 14 & 50 \\
\hline Group 3-4 & 7 & 25 \\
\hline
\end{tabular}

CHOP, their peripheral-blood stem-cells were collected and subsequent HDT and ASCT indicated. The third cycle of Double-CHOP regimen was used for stem cell mobilization. Consolidating HDT regimen consisted of cyclophosphamide (60 mg/kg, day -7 and -6 , i.v. $>3 \mathrm{~h}$ ), etoposide $\left(500 \mathrm{mg} / \mathrm{m}^{2}\right.$; day $-6,-5$, and -4 ; i.v. $>6-8 \mathrm{~h})$, and ranimustine $\left(250 \mathrm{mg} / \mathrm{m}^{2}\right.$, day -3 and -2 , i.v. $>1$ h). ASCT was performed on day 0 and G-CSF administered from day 1 until neutrophil engraftment. As an alternative to HDT/ASCT, HDMTX $\left(8 \mathrm{~g} / \mathrm{m}^{2}\right.$, day 1 , i.v. $>4 \mathrm{~h}$ ) was indicated for patients who could not yield a sufficient number of stem cells or were ineligible for HDC.

Treatment response and toxicity. Response to Double-CHOP regimen was assessed by physical examination, CT scanning, and either gallium scintigraphy or PET before ASCT indication. Patients were classified based on achieving $\mathrm{CR} / \mathrm{CRu}$, partial 
A
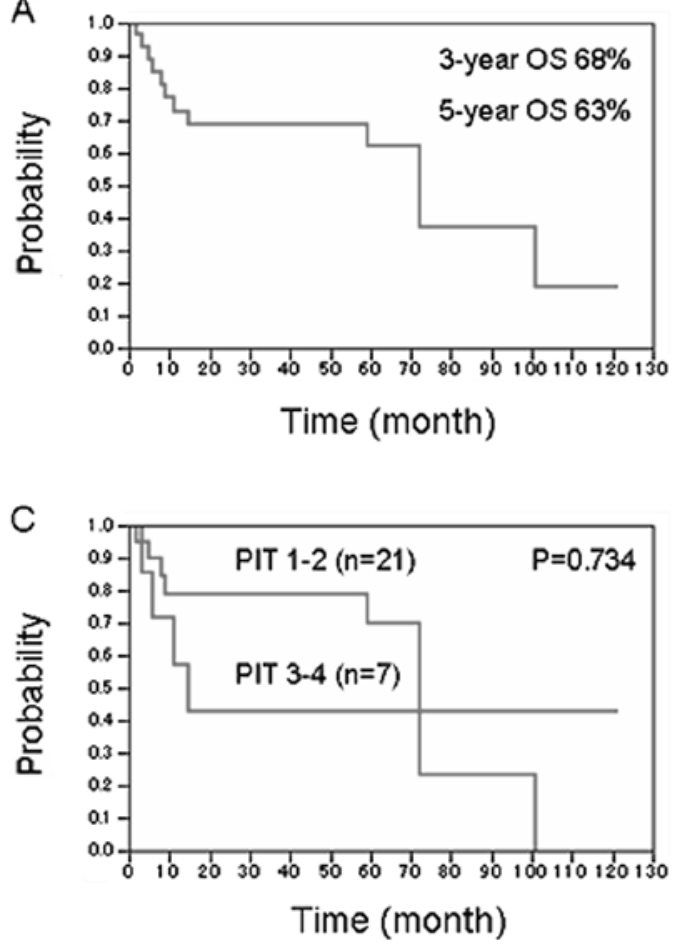

B
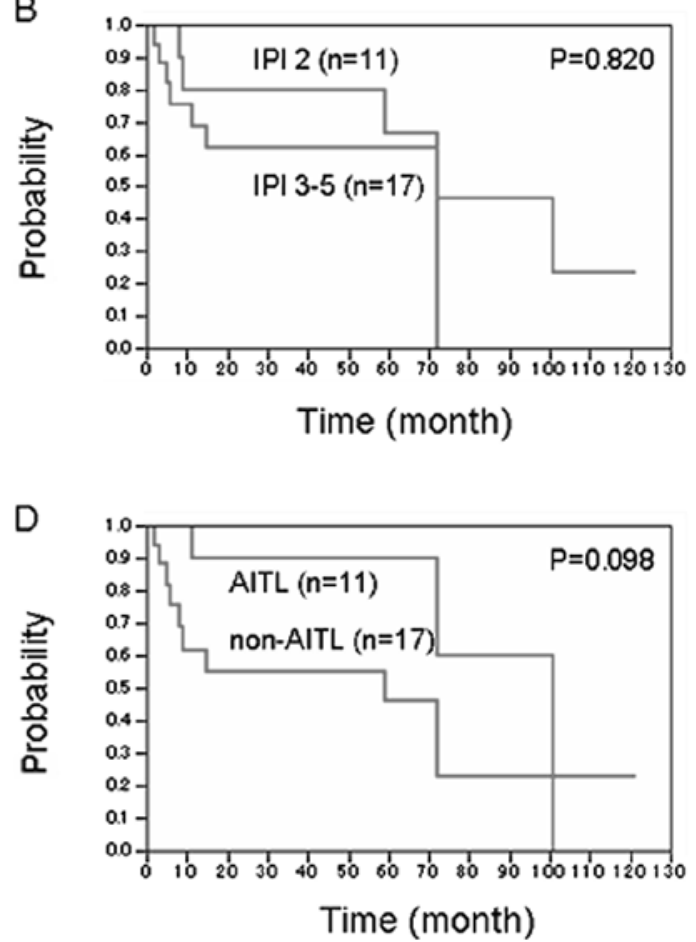

Figure 1. Overall survival (OS) curves for all patients (A) according to IPI risk factor (B), PIT score (C), and OS comparison between AITL and non-AITL (D).

response (PR), stable disease (SD), or progressive disease (PD), according to the criteria previously reported by Cheson et al (20). Patients remained in the hospital until achieving haematological recovery in each chemotherapy cycle. Blood and physical examinations were performed more than twice per week. Toxicity related to the Double-CHOP regimen was evaluated according to the National Cancer Institute Common Terminology Criteria for Adverse Events, version 4.0.

Statistical analyses. The patients OS was calculated from treatment initiation to the date of death or until follow-up termination. Relapse-free survival (RFS) for patients who achieved $\mathrm{CR}$ was calculated from the date of the last treatment or ASCT to either the recurrence date or the follow-up termination. OS and RFS were calculated according to the Kaplan-Meier method. Prognostic factors likely affecting clinical outcomes were analysed by univariate Cox proportional-hazard regression model. Statistical analyses were performed using the JMP software, version 8.0.1 (SAS Institute Inc., Cary, NC, USA).

\section{Results}

Patients. Twenty-eight consecutive PTCL patients, including 13 PTCL-NOS, 11 AITL, 3 ALK-ALCL patients, and $1 \gamma / \delta$ T-cell lymphoma patient, were enrolled in this study. Misdiagnosed patients, patients with other T-cell lymphoma subtypes, or those treated with alternative regimens, were excluded. Patients were mostly male (20 men and 8 women) and aged 17-69 years (median: 58 years). Regarding IPI and PIT scores, 11 (39\%), $10(36 \%)$, and $7(25 \%)$ patients were at low-intermediate, high-intermediate, and high IPI risk, respectively. Seven (25\%) patients had $\geq 3$ PIT scores. Patients who required immediate treatment because of a poor ECOG PS likely caused by an underlying disease or rapid disease progression, were indicated to receive the standard CHOP regimen before Double-CHOP treatment. Similarly, because many patients required immediate administration of therapeutic agents, we modified the treatment protocol to initiate standard CHOP followed with 3 courses of Double-CHOP, in 2003. Overall, 23 patients received standard CHOP before Double-CHOP. Patients characteristics are reported in Table I.

CR rate and consolidation therapy. After Double-CHOP treatment, 19 (68\%) patients achieved CR/CRu, 4 PR, 1 NC, and 3 PD. Unfortunately, 1 patient died of septicaemia during the treatment term. Of 19 patients with $\mathrm{CR} / \mathrm{CRu}, 10$ were given G-CSF to allow harvesting of CD34-positive cells. Eight (80\%) patients yielded high numbers of CD34-positive stem cells $\left(>2.0 \times 10^{6} / \mathrm{kg}\right)$ after Double-CHOP. Two patients were poorly mobilised by G-CSF, but yielded acceptable numbers of stem cells by a harvest regimen using VP-16. Overall, all patients aged $\leq 65$ years underwent CR/CRu and received ASCT. For patients aged $>65$ years, HDMTX was administered instead of $\operatorname{ASCT}(n=7)$. Two patients with unacceptable ECOG PS experienced early relapse after CR and were excluded from HDMTX or ASCT treatment.

OS and risk factor. The follow-up term ranged from 4 to 123 months (median, 31 months). Since treatment initiation, the 3- and 5-year OS were 68 and 63\%, respectively (Fig. 1A). No significant differences in OS were observed between low-intermediate and high-intermediate to high IPI-risk groups (Fig. 1B). Moreover, the PIT score did not affect OS or IPI risk factors (Fig. 1C). When comparing different PTCL 

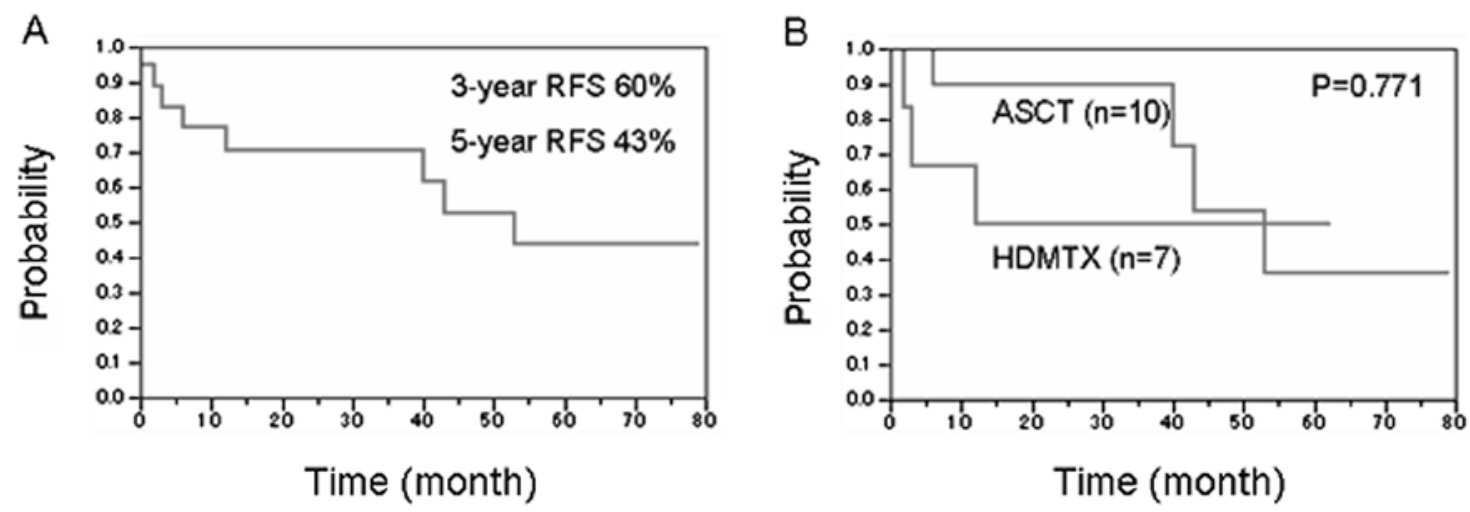

Figure 2. Relapse-free survival curves for all patients who obtained complete remission (A) and followed consolidation therapies (B).

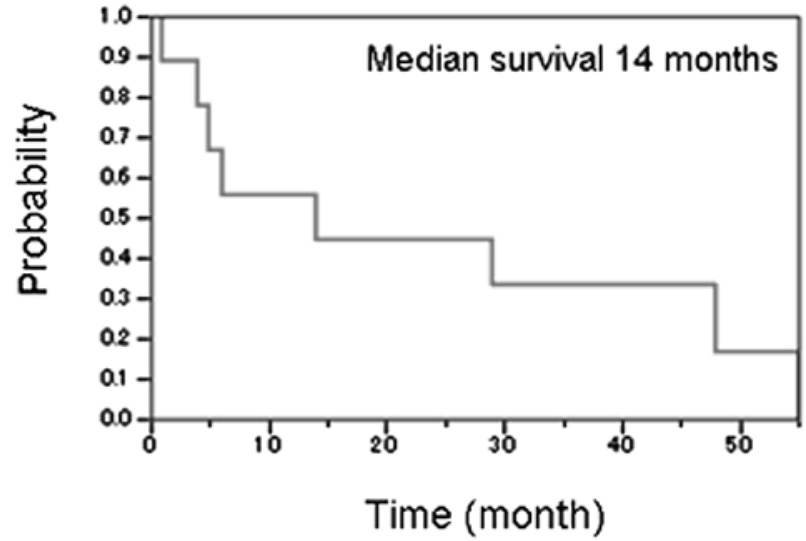

Figure 3. Overall survival curve after relapse. Data were calculated from relapse time to follow-up termination or death.

subtypes, AITL tended to show a more favourable prognosis than did other subtypes, but this difference was statistically insignificant (Fig. 1D). The major cause of death was disease progression or treatment-related toxicity. One case treated with HDT/ASCT developed a secondary malignancy (acute leukaemia) after experienced lymphoma relapse and received salvage chemotherapy, and the patient died of leukaemia.

RFS. Among 19 patients in complete remission, the calculated 3- and 5-year RFS were 60 and 43\% at treatment termination, respectively (Fig. 2A). No treatment-related mortality cases following HDMTX or HDT/ASCT ensued. RFS data for patients who underwent HDT/ASCT $(n=10)$ or HDMTX $(n=7)$ are shown in Fig. 2B. Three- and 5-year RFS estimations in the former and latter group were 68 and 58\%, and 53 and 40\%, respectively. No significant differences were observed between these 2 groups; however, the HDMTX group, including patients aged $>65$ years, likely relapsed earlier than those who received HDT/ASCT.

Prognosis for relapsing patients. It has been reported that in patients not receiving upfront ASCT, salvage regimen followed by ASCT is often a promising treatment strategy $(13,14)$. However, patients who relapsed after treatment with intensive chemotherapy and upfront ASCT or HDMTX in our study showed poor prognoses (Fig. 3). Of 9 relapsing patients, 8 received salvage chemotherapy and 2 were subsequently treated with cord-blood transplantation (CBT). Nevertheless, of those undergoing CBT, 1 died of fungal infection and a second patient died of disease progression within 3 months. Only 1 of 9 relapsing cases was still alive with disease after follow-up termination.

Prognosis for non-CR patients. Apart from 19 patients achieving CR and a single case of treatment-related mortality, 4 underwent PR, $1 \mathrm{NC}$, and 3 experienced PD. One patient received ASCT after PR, but did not achieve CR after treatment completion while experiencing early PD (within 2 months). In contrast, 1 patient who received ASCT following CR after salvage therapy achieved RFS of over 2 years. Of 4 patients who received allogeneic hematopoietic cell transplantation (HSCT), 3 underwent BMT and 1 CBT. Three of 4 did not achieve CR following transplantation; however, all patients achieved and maintained CR after HSCT. Our results are particularly noteworthy because we showed clinical efficacy for allogeneic HSCT in PTCL patients who did not achieve CR after initial treatment.

Toxicity. Treatment-related toxicity was monitored in all patients throughout the Double-CHOP duration. The major DoubleCHOP-related toxicity events were bone marrow suppression and infection. Grade 3 or grade 4 neutropaenia, anaemia, and thrombocytopaenia were also common. Thus, all patients required G-CSF administration. Some patients experienced febrile neutropaenia $(n=18)$, pneumonia $(n=3)$, or septicaemia $(n=2)$, along with haematological toxicity. All but one septicaemic patient recovered after receiving wide-spectrum antibiotics. Non-haematological toxicities such as nausea, diarrhoea, electrolyte abnormalities, or liver dysfunctions were also reported, but these were reversible. Patients toxicity records are shown in Table II.

\section{Discussion}

CHOP or CHOP-like therapy regimes have previously been used to treat PTCLs. However, patients outcomes, particularly in high-intermediate or high-risk cases as defined by age-adjusted IPI, have reportedly been a poor 5-year OS of 
Table II. Significant toxicities associated with D-CHOP regimen.

\begin{tabular}{cccc}
\hline Total & & Age $\geq 60$ \\
$(\mathrm{n}=28)$ & $\%$ & $(\mathrm{n}=10)$ & $\%$ \\
\hline
\end{tabular}

\section{Leukopaenia}

Grade 4

Neutropaenia

Grade 4

Anaemia

Grade 3

Grade 4

Thrombocytopaenia

Grade 3

Grade 4

Liver dysfunction (AST/

ALT/Total Bilirubin elevation)

Grade 3
Grade 4

Electrolyte abnormality

(serum $\mathrm{Na}$ and/or K)

Grade 3

Grade 4

Febrile neutropaenia

\begin{tabular}{lrrrr} 
Grade 3 & 18 & 64 & 4 & 40 \\
Grade 4 & 0 & 0 & 0 & 0 \\
Septicaemia & & & & \\
Grade 4 & 1 & 4 & 0 & 0 \\
Grade 5 & 1 & 4 & 0 & 0 \\
Pneumonia & & & & \\
Grade 3 & 3 & 11 & 0 & 0 \\
Grade 4 & 0 & 0 & 0 & 0 \\
Gastrointestinal disorder & & & & \\
Grade 3 & 2 & 7 & 1 & 10 \\
Grade 4 & 0 & 0 & 0 & 0 \\
Peripheral neuropathy & & & & \\
Grade 3 & 3 & 10 & 1 & 11 \\
Grade 4 & 0 & 0 & 0 & 0 \\
\hline
\end{tabular}

$<40 \%$ (10,21). Furthermore, despite multiple retrospective studies, improving patients prognoses remains an eminent challenge. Major treatment strategies attempting to improve patient outcome have been classified into 4 groups: i) intensive treatment, ii) upfront ASCT, iii) allogeneic HSCT, and iv) use of novel agents. ASCT is often more effective when patient's clinical status is documented and controlled well before therapy initiation $(15-18,22,23)$, indicating that chemotherapy-sensitive disease can be suppressed effectively with intensive consolidation therapies. Highly improved RFS and OS reported in our study support the fact that a welldocumented disease status is quintessential for improving CR rates by administering Double-CHOP and intensive high-dose therapy regimens.
Contrarily, a previous German High-Grade Non-Hodgkin Lymphoma Study Group (DSHNHL) report demonstrated that a dose-intensified CHOEP (CHOP plus etoposide) regimen followed by ASCT resulted in poor survival rates compared with a standard-dose CHOEP regimen (24). Although our protocol was similar to that used in this study, our recorded OS results appear to be better than those reported for standard CHOP regimens. The reasons for discordant results between this study and ours remain elusive, while case numbers in both studies were relatively small. Therefore, conducting largescale studies is required to ascertain the efficacy of intensified regimens better. Our results also emphasise that the efficacy of dose-intensified regimen(s) for PTCLs should be re-evaluated to improve patients prognoses.

Our patients inclusion criteria are noteworthy because we included a broad age group ( $<70$ years; median: 58 years) and excluded low-risk IPI and ALK ${ }^{+}$-ALCL patients. As shown in Table I, our patients clinical characteristics were worse than those in previous reports, which used multi-agent chemotherapy with or without ASCT $(16,18)$. Dose-modified CHOP was well tolerated and effective in elderly patients included in our study, indicating the importance of individualised dose modifications or intensifications. Although our study could not determine an association between prognosis and IPI risk factor and PIT score, patients outcomes are altered expectedly with distinct treatment protocols. Consequently, the Double-CHOP regimen may be more effective for PTCL patients with likely poor prognostic factors.

We did not find a significant difference in relapse rate or other events between ASCT- and HDMTX-treated groups, which included patients younger or older than 65 years of age. Nevertheless, patients who received ASCT tended to relapse later than those who received HDMTX instead of ASCT. These different trends suggest that a more intensive consolidation therapy may be the means to sustain a prolonged disease-free status. On the contrary, it is uncertain whether an intensified treatment may increase the curative rates as shown by plateauing Kaplan-Meier curve in Figs. 1 and 2. In addition, an optimised treatment strategy should follow relapse when an intensified treatment regimen, including upfront ASCT, was previously applied. ASCT after disease control by salvage therapy has been shown to be a favourable treatment strategy in both B- and T-cell lymphomas $(13,14)$. However, prognoses in our relapsing patients who received intensified treatment were unfavourable, showing a median 14-month OS following relapse. Most cases receiving salvage chemotherapy were refractory and finally died of disease progression. In such cases, rapid preparation for allogeneic HSCT should be explored. In addition, these patients, especially elderly patients who are not good HSCT candidates (e.g. over 65 years), are ideal candidates for trialling new agents.

We have previously demonstrated that refractory diffuse large B-cell lymphoma (DLBCL) is less favourable than relapsing DLBCL (25). Reportedly, the primary refractory and non-CR patients are likely better off than relapsing patients. Four of 7 patients received allogeneic HSCT on CR or non-CR and resulted only in a single case of treatment-related mortality while 3 survived. Despite a relatively small number of successful cases, we could surmise that rapid decision-making may significantly improve patients outcomes, if they were clini- 
cally resistant to chemotherapy. Previous studies demonstrated results of allogeneic HSCT for PTCLs showing that donor lymphocyte infusion was effective, indicating a graft versus T-cell lymphoma effect $(26,27)$. Our cases achieved CR after allogeneic HSCT underscoring the presence of a graft versus T-cell lymphoma effect, and the need for lowering the decisionmaking threshold to indicate allogeneic HSCT under refractory settings. If patient's status was well sustained and a donor was available, allogeneic HSCT may be a curative strategy for refractory PTCLs. Of note, no recommendations can be made regarding alternative donor transplants due to data paucity. Therefore, alternative donor transplants should be considered as a clinical trial.

In conclusion, our data suggest that 3 cycles of DoubleCHOP regimen may improve complete remission in patients with PTCLs. According to our experience involving DLBCL $(28,29)$, Double-CHOP followed by ASCT/HDMTX consolidations is safe and may achieve prolonged RFS, especially in patients with poor prognostic factors. Since case numbers are relatively small, we cannot confirm the ASCT impact. Moreover, prospective PTCL studies involving ASCT and allogeneic HSCT are needed. To address these issues further, well-designed, large-scale, prospective studies are required.

\section{References}

1. Coiffier B, Brousse N, Peuchmaur M, Berger F, Gisselbrecht C, Bryon PA and Diebold J: Peripheral T-cell lymphomas have a worse prognosis than B-cell lymphomas: a prospective study of 361 immunophenotyped patients treated with the LNH-84 regimen. The GELA (Groupe d'Etude des Lymphomes Agressives). Ann Oncol 1: 45-50, 1990.

2. Vose J, Armitage J and Weisenburger D: International T-Cell Lymphoma Project: International peripheral T-cell and natural killer/T-cell lymphoma study: pathology findings and clinical outcomes. J Clin Oncol 26: 4124-4130, 2008.

3. Sehn LH, Donaldson J, Chhanabhai M, Fitzgerald C, Gill K, Klasa R, MacPherson N, O'Reilly S, Spinelli JJ, Sutherland J, Wilson KS, Gascoyne RD and Connors JM: Introduction of combined CHOP plus rituximab therapy dramatically improved outcome of diffuse large B-cell lymphoma in British Columbia. $\mathrm{J}$ Clin Oncol 23: 5027-5033, 2005.

4. Feugier P, Van Hoof A, Sebban C, Solal-Celigny P, Bouabdallah R, Ferme C, Christian B, Lepage E, Tilly H, Morschhauser F, Gaulard P, Salles G, Bosly A, Gisselbrecht C, Reyes F and Coiffier B: Long-term results of the R-CHOP study in the treatment of elderly patients with diffuse large B-cell lymphoma: a study by the Groupe d'Etude des Lymphomes de l'Adulte. J Clin Oncol 23: 4117-4126, 2005.

5. Gascoyne RD, Aoun P, Wu D, Chhanabhai M, Skinnider BF Greiner TC, Morris SW, Connors JM, Vose JM, Viswanatha DS, Coldman A and Weisenburger DD: Prognostic significance of anaplastic lymphoma kinase (ALK) protein expression in adults with anaplastic large cell lymphoma. Blood 93: 3913-3921, 1999.

6. Falini B, Pileri S, Zinzani PL, Carbone A, Zagonel V, WolfPeeters C, Verhoef G, Menestrina F, Todeschini G, Paulli M, Lazzarino M, Giardini R, Aiello A, Foss HD, Araujo I, Fizzotti M, Pelicci PG, Flenghi L, Martelli MF and Santucci A: $\mathrm{ALK}^{+}$lymphoma: clinico-pathological findings and outcome. Blood 93: 2697-2706, 1999.

7. Willemze R, Jaffe ES, Burg G, Cerroni L, Berti E, Swerdlow SH, Ralfkiaer E, Chimenti S, Diaz-Perez JL, Duncan LM, Grange F, Harris NL, Kempf W, Kerl H, Kurrer M, Knobler R, Pimpinelli N, Sander C, Santucci M, Sterry W, Vermeer MH, Wechsler J, Whittaker S and Meijer CJ: WHO-EORTC classification for cutaneous lymphomas. Blood 105: 3768-3785, 2005.

8. Jenni D, Karpova MB, Seifert B, Golling P, Cozzio A, Kempf W, French LE and Dummer R: Primary cutaneous lymphoma: twodecade comparison in a population of 263 cases from a Swiss tertiary referral centre. Br J Dermatol 164: 1071-1077, 2011.
9. Abouyabis AN, Shenoy PJ, Lechowicz MJ and Flowers CR: Incidence and outcomes of the peripheral T-cell lymphoma subtypes in the United States. Leuk Lymphoma 49: 2099-2107, 2008.

10. Weisenburger DD, Savage KJ, Harris NL, Gascoyne RD, Jaffe ES, MacLennan KA, Rüdiger T, Pileri S, Nakamura S, Nathwani B, Campo E, Berger F, Coiffier B, Kim WS, Holte H, Federico M, Au WY, Tobinai K, Armitage JO and Vose JM: International Peripheral T-cell Lymphoma Project: Peripheral T-cell lymphoma, not otherwise specified: a report of 340 cases from the International Peripheral T-cell Lymphoma Project. Blood 117: 3402-3408, 2011.

11. Gisselbrecht C, Gaulard P, Lepage E, Coiffier B, Brière J, Haioun C, Cazals-Hatem D, Bosly A, Xerri L, Tilly H, Berger F, Bouhabdallah R and Diebold J: Prognostic significance of T-cell phenotype in aggressive non-Hodgkin's lymphomas. Groupe d'Etudes des Lymphomes de l'Adulte (GELA). Blood 92: 76-82, 1998.

12. Fisher RI, Gaynor ER, Dahlberg S, Oken MM, Grogan TM, Mize EM, Glick JH, Coltman CA Jr and Miller TP: Comparison of a standard regimen (CHOP) with three intensive chemotherapy regimens for advanced non-Hodgkin's lymphoma. N Engl J Med 328: 1002-1006, 1993.

13. Kewalramani T, Zelenetz AD, Teruya-Feldstein J, Hamlin P, Yahalom J, Horwitz S, Nimer SD and Moskowitz CH: Autologous transplantation for relapsed or primary refractory peripheral T-cell lymphoma. Br J Haematol 134: 202-207, 2006.

14. Song KW, Mollee P, Keating A and Crump M: Autologous stem cell transplant for relapsed and refractory peripheral T-cell lymphoma: variable outcome according to pathological subtype. Br J Haematol 120: 978-985, 2003.

15. Hosing $C$ and Champlin RE: Stem-cell transplantation in T-cell non-Hodgkin's lymphomas. Ann Oncol 22: 1471-1477, 2011.

16. Casulo $C$ and Horwitz S: Should eligible patients with T-cell lymphoma receive high-dose therapy and autologous stem cell transplant in the upfront setting? Curr Oncol Rep 12: 374-382, 2010.

17. Savage KJ: Therapies for peripheral T-cell lymphomas. Hematology Am Soc Hematol Educ Program 2011: 515-524, 2011.

18. Reimer P: Impact of autologous and allogeneic stem cell transplantation in peripheral T-cell lymphomas. Adv Hematol 2010: 320624, 2010.

19. Moskowitz AJ and Moskowitz $\mathrm{CH}$ : Controversies in the treatment of lymphoma with autologous transplantation. Oncologist 14: 921-929, 2009.

20. Cheson BD, Horning SJ, Coiffier B, Shipp MA, Fisher RI, Connors JM, Lister TA, Vose J, Grillo-López A, Hagenbeek A, Cabanillas F, Klippensten D, Hiddemann W, Castellino R, Harris NL, Armitage JO, Carter W, Hoppe R and Canellos GP: Report of an international workshop to standardize response criteria for non-Hodgkin's lymphomas. NCI Sponsored International Working Group. J Clin Oncol 17: 1244-1253, 1999.

21. Ansell SM, Habermann TM, Kurtin PJ, Witzig TE, Chen MG, Li CY, Inwards DJ and Colgan JP: Predictive capacity of the International Prognostic Factor Index in patients with peripheral T-cell lymphoma. J Clin Oncol 15: 2296-2301, 1997.

22. Yang DH, Kim WS, Kim SJ, Bae SH, Kim SH, Kim IH, Yoon SS, Mun YC, Shin HJ, Chae YS, Kwak JY, Kim H, Kim MK, Kim JS, Won JH, Lee JJ and Suh CW: Prognostic factors and clinical outcomes of high-dose chemotherapy followed by autologous stem cell transplantation in patients with peripheral $\mathrm{T}$ cell lymphoma, unspecified: complete remission at transplantation and the prognostic index of peripheral $\mathrm{T}$ cell lymphoma are the major factors predictive of outcome. Biol Blood Marrow Transplant 15: 118-125, 2009.

23. Corradini P, Tarella C, Zallio F, Dodero A, Zanni M, Valagussa P, Gianni AM, Rambaldi A, Barbui T and Cortelazzo S: Long-term follow-up of patients with peripheral T-cell lymphomas treated up-front with high-dose chemotherapy followed by autologous stem cell transplantation. Leukemia 20: 1533-1538, 2006.

24. Pfreundschuh M, Zwick C, Zeynalova S, Dührsen U, Pflüger KH, Vrieling T, Mesters R, Mergenthaler HG, Einsele H, Bentz M, Lengfelder E, Trümper L, Rübe C, Schmitz N and Loeffler M: German High-Grade Non-Hodgkin's Lymphoma Study Group (DSHNHL): Dose-escalated CHOEP for the treatment of young patients with aggressive non-Hodgkin's lymphoma: II. Results of the randomized high-CHOEP trial of the German High-Grade Non-Hodgkin's Lymphoma Study Group (DSHNHL). Ann Oncol 19: 545-552, 2008. 
25. Miura K, Takei K, Kobayashi S, Kiso S, Hirabayashi Y, Hojo A Kodaira H, Yagi M, Kurita D, Kobayashi Y, Tanaka T, Iriyama N, Hatta Y, Kura Y, Yamazaki T, Sawada U and Takeuchi J: An effective salvage treatment using ifosfamide, etoposide, cytarabine, dexamethasone, and rituximab (R-IVAD) for patients with relapsed or refractory aggressive B-cell lymphoma. Int J Hematol 94: 90-96, 2011

26. Corradini P, Dodero A, Zallio F, Caracciolo D, Casini M, Bregni M, Narni F, Patriarca F, Boccadoro M, Benedetti F, Rambaldi A, Gianni AM and Tarella C: Graft-versus-lymphoma effect in relapsed peripheral T-cell non-Hodgkin's lymphomas after reduced-intensity conditioning followed by allogeneic transplantation of hematopoietic cells. J Clin Oncol 22: 2172-2176, 2004.

27. Wulf GG, Hasenkamp J, Jung W, Chapuy B, Truemper L and Glass B: Reduced intensity conditioning and allogeneic stem cell transplantation after salvage therapy integrating alemtuzumab for patients with relapsed peripheral T-cell non-Hodgkin's lymphoma. Bone Marrow Transplant 36: 271-273, 2005.
28. Yamazaki T, Sawada U, Kura Y, Ito T, Kaneita Y, Yasukawa K and Horie T: Dose-intensified CHOP (double-CHOP) followed by consolidation with high-dose chemotherapy for high and high-intermediate risk aggressive non-Hodgkin's lymphomas. Leuk Lymphoma 43: 2117-2123, 2002.

29. Yamazaki T, Sawada U, Kura Y, Ito T, Takeuchi J, Hatta Y, Aikawa S, Takei K, Ishizuka H, Saiki M and Uenogawa K: Treatment of high-risk peripheral T-cell lymphomas other than anaplastic large-cell lymphoma with a dose-intensified CHOP regimen followed by high-dose chemotherapy. A single institution study. Acta Haematol 116: 90-95, 2006. 